\title{
The Compilation and Execution of a Measurement of Chinese Undergraduates' Moral Values Approval
}

\author{
Zhu Hai-Long (Guangdong University of Foreign Studies)
}

\section{Introduction}

Values education is the core content of the college students' moral education in China. Significant as it is, scholars have carried out relevant researches for a long time. Since the values of college students are related to their psychological cognition and cannot be judged directly, we can only explore values from explicit phenomenon that may add some special zest to the value studies. This situation prevails to a large extent, and the researchers in this field in China still remain at the stage of judging one's values from one phenomenon to another. There are neither many qualitative researches nor positive or sufficient quantitative ones, regardless any mature research findings. The scale measuring moral values and reflecting the characteristics of Chinese College Students' cognition can be applied to imperative practices in universities. With this view, the article attempts to formulate a Chinese Moral Value Identity Scale, and carry out exploratory survey with such scale among college students in China.

\section{Collecting and Ranking Moral Values' Articulation Through the Open Type of Questionnaire}

Combined with Chinese moral value vocabulary collected from moral education experts, first-tier teachers and college students, we formulated an open type of questionnaire which asked questions like "what do you think are Chinese moral value mostly agreed among college students? Please list 5 of the moral vocabulary." The survey was conducted at Sun Yat Sen University, Beijing Normal University, Xinjiang Normal University and Changsha Normal College. The survey aimed at undergraduate students as research subjects. Using random cluster samplings, 300 questionnaires were administered and collected right on the spot. There were 286 valid questionnaires collected with an efficacy rate of $95.3 \%$. After screening, we sorted out 56 effective value words in total According to the frequency ranking from high to low, we selected the top 10 words depicting Chinese traditional core moral values, Filial piety came up as a word with the highest frequency, followed by diligence, integrity, kindness, patriotism, humility, civilization, rituality, courage, unity and respect. 


\section{Preparation for the Initial Scale Based on the Core Value Vocabulary}

After getting 10 moral value words, we sent out 240 open type- questionnaires to full-time undergraduates at Beijing Normal University, Guangdong University of Foreign Studies, Xinjiang Normal University, and Changsha Normal College. The numbers of male and female respondents were equally halved. College students were asked to list five corresponding moral behavior in each kind of value vocabulary. For example, the students may write down the following statements "I think accompanying parents to chat regularly is the expression of college students respecting the parents." We collected the questionnaires on the spot, and rejected those unfinished questionnaires. 214 effective questionnaires were collected with an efficacy rate of $89.2 \%$. After collecting the questionnaires, we consolidated the statistics for every core moral value words corresponding to moral behavior, and sifted words with similar meanings. According to the frequency of the top five kinds of moral behavior, we prepare the initial questionnaire of college students' moral values. Each core moral value is a basic dimension corresponding to five kinds of moral behavior with five questions. 10 value terms in total were distributed among 50 questions. We made different moral dimensions of subject cross arrangement, using Likert 5-scoring method, i.e. $1=$ completely disagree, 2 = disagree, $3=$ uncertain, $4=$ agree, $5=$ completely agree and set inverse questions, and formulated the initial questionnaire.

\section{The Test for Reliability and Validity of the Initial Scale, and the Preparation of the Formal Scale}

\subsection{The test for reliability and validity}

Through the initial scale pretesting, we verified the reliability and validity. The test respondents were undergraduate students of Guangdong University of Foreign Studies and Sun Yat Sen University. We used random cluster sampling and sent out 100 questionnaires in person. The time for the test was about 30 minutes, and we collected questionnaires on the spot. There were 86 valid questionnaires that were later processed by SPSS16.0 for statistical analysis. The results show that the reliability of initial scale are Cronbach alpha 0.887 and Spearman Brown split half reliability 0.776. In the verifying test, we invited the moral education experts, first-tier teachers of moral education to evaluate the correction of each project repeatedly, for the scale of the surveying project was formulated from related literature, findings of open questionnaire and interview survey results. It can have good content validity. At the same time, KMO and Bartlett test of sphericity can verify the construct validity of the initial scale. According to the criteria of the statistical measure, the closer to 1 
KMO value is, the stronger correlation between variables are. The scale has its structure validity and the original variables are more suitable for factor analysis. The measuring results show that $\mathrm{KM} 0=0.830, \mathrm{P}<0.01$, indicating that the initial scale has good construct validity.

\subsection{The preparation of the official scale}

After verifying that the initial scale has good reliability and validity, we then started the factor analysis, using the independent samples $\mathrm{T}$ to test. According to the situation of factor load, we removed some poorly related differentiating questions, and statistics showed that the P of T7, T10, T14 and T15, T18, T21, $\mathrm{T} 22, \mathrm{~T} 24, \mathrm{~T} 30, \mathrm{~T} 31, \mathrm{~T} 38, \mathrm{~T} 40, \mathrm{t} 44, \mathrm{~T} 50>0.05$. That is to say, differentiating result of these questions was poor so it needs to be deleted, and there were remaining 36 questions. In order to confirm the dimensions of factor from the remaining questions in the questionnaire, it need to conduct the exploratory factor analysis, select the principal component analysis method, choose characterization value which is bigger than 1 as the dimension and use maximum variance method to do orthogonal rotation identified rotated factor contribution, as Table 1 shows: 
The Compilation and Execution of a Measurement of Chinese Undergraduates'...

\begin{tabular}{|c|c|c|c|c|c|c|}
\hline \multicolumn{4}{|c|}{ Initial Eigenvalues } & \multicolumn{3}{|c|}{ Extraction Sums of Squared Loadings } \\
\hline $\begin{array}{l}\text { Compo- } \\
\text { nent }\end{array}$ & Total & $\begin{array}{l}\% \text { of } \\
\text { variance }\end{array}$ & Cumulative \% & Total & $\begin{array}{l}\% \text { of } \\
\text { variance }\end{array}$ & $\begin{array}{l}\text { Cumula- } \\
\text { tive } \%\end{array}$ \\
\hline 1 & 6.887 & 19.131 & 19.131 & 1.887 & 19.131 & 19.131 \\
\hline 2 & 2.373 & 6.592 & 25.723 & 2.373 & 6.592 & 25.723 \\
\hline 3 & 2.335 & 6.486 & 32.209 & 2.335 & 6.486 & 32.209 \\
\hline 4 & 2.037 & 5.657 & 37.866 & 2.037 & 5.657 & 37.866 \\
\hline 5 & 1.747 & 4.852 & 42.718 & 1.747 & 4.852 & 42.718 \\
\hline 6 & 1.585 & 4.403 & 47.120 & 1.585 & 4.403 & 47.120 \\
\hline 7 & 1.495 & 4.153 & 51.273 & 1.495 & 4.153 & 51.273 \\
\hline 8 & 1.470 & 4.082 & 55.356 & 1.470 & 4.082 & 55.356 \\
\hline 9 & 1.343 & 3.731 & 62.087 & 1.343 & 3.731 & 62.087 \\
\hline 10 & 1.224 & 3.400 & 71.487 & 1.224 & 3.400 & 71.487 \\
\hline 11 & 1.193 & 3.314 & 77.801 & 1.193 & 3.314 & 77.801 \\
\hline 12 & 1.074 & 2.985 & 81.785 & 1.074 & 2.985 & 81.785 \\
\hline 13 & .951 & 2.642 & 71.427 & & & \\
\hline 14 & .943 & 2.620 & 74.048 & & & \\
\hline 15 & .821 & 2.281 & 76.329 & & & \\
\hline 16 & .796 & 2.212 & 78.541 & & & \\
\hline 17 & .736 & 2.045 & 80.586 & & & \\
\hline 18 & .721 & 2.003 & 82.589 & & & \\
\hline 19 & .662 & 1.839 & 84.428 & & & \\
\hline 20 & .598 & 1.660 & 86.088 & & & \\
\hline 21 & .567 & 1.574 & 87.662 & & & \\
\hline 22 & .516 & 1.434 & 89.097 & & & \\
\hline 23 & .489 & 1.359 & 90.456 & & & \\
\hline 24 & .445 & 1.237 & 91.693 & & & \\
\hline 25 & .421 & 1.169 & 92.861 & & & \\
\hline 26 & .387 & 1.075 & 93.936 & & & \\
\hline 27 & .366 & 1.017 & 94.954 & & & \\
\hline 28 & .321 & .890 & 95.844 & & & \\
\hline 29 & .288 & .801 & 96.645 & & & \\
\hline 30 & .258 & .717 & 97.362 & & & \\
\hline 31 & .214 & .594 & 97.955 & & & \\
\hline 32 & .202 & .562 & 98.518 & & & \\
\hline $\begin{array}{c}33 \\
96\end{array}$ & .171 & .475 & 98.993 & & & \\
\hline 34 & .149 & .413 & 99.406 & & & \\
\hline 35 & .124 & .344 & 99.750 & & & \\
\hline 36 & .090 & .344 & 100.00 & & & \\
\hline
\end{tabular}


Table 1. Extracting factors (Total Variance Explained)

Based on process taking by rule that characteristic value is bigger than 1 , it can explain the 12 principal components and summarize most of the information on scree plot for analysis. From the table, it shows that 1 to 12 principal feature values are bigger than 1 :

\section{Scree Plot}

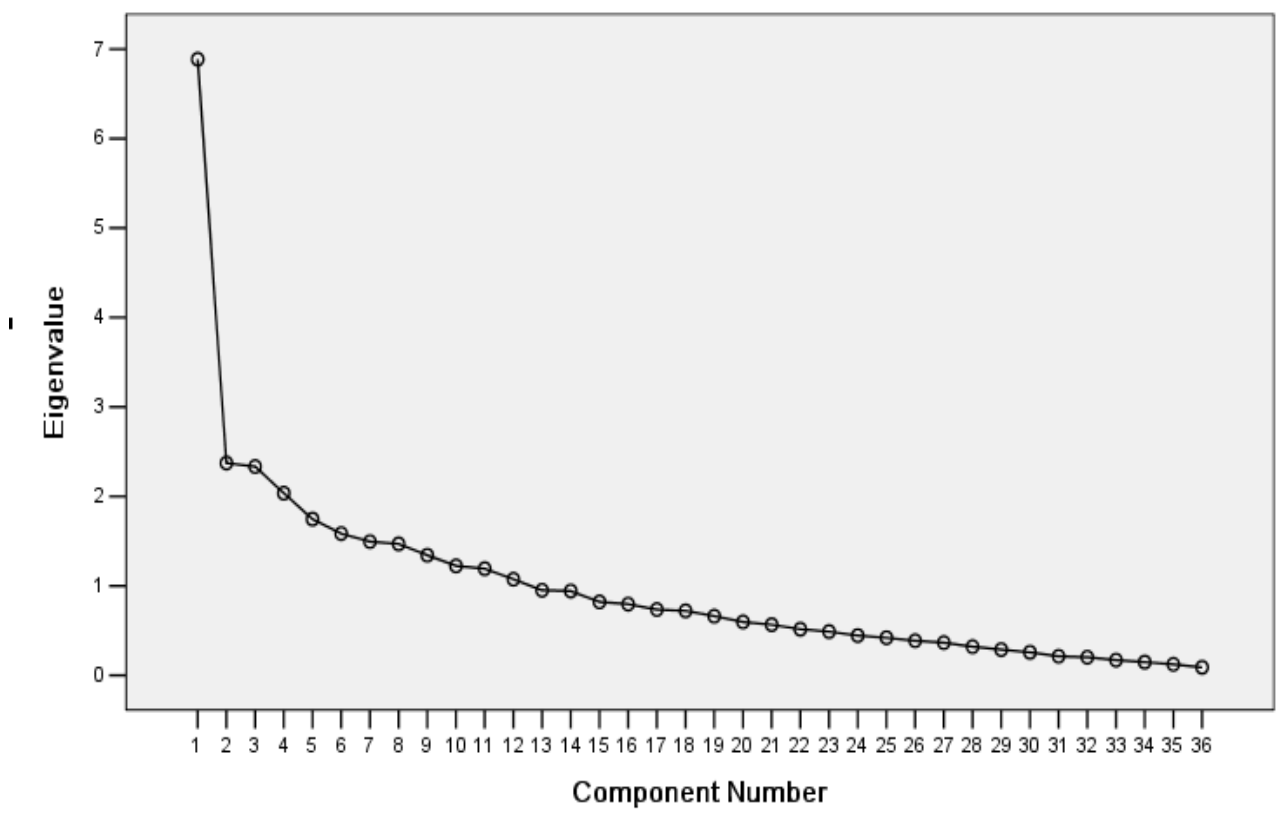

Chart 1. Scree plot

Scree plot indicated the eigenvalue varying significantly among the first 12 common factors. From the 13th factor on, its eigenvalue began to vary steadily, so the extraction of 12 original variables description has obvious effect of common factor. In order to facilitate the explanation of common factor, we can make a Rotated Component Matrix(a), and the results are shown in Table 2. 
Table 2. The Results of Rotated Component Matrix(a).

\begin{tabular}{|c|c|c|c|c|c|c|c|c|c|c|c|c|}
\hline & 1 & 2 & 3 & 4 & 5 & 6 & 7 & 8 & 9 & 10 & 11 & 12 \\
\hline T3 & .766 & & & & & & & & & & & \\
\hline $\mathrm{T} 2$ & .697 & & & & & & & & & & & \\
\hline T8 & .545 & & & & & & & & & & & \\
\hline T3 & .514 & & & & & & & & & & & \\
\hline $\mathrm{T} 4$ & .511 & & & & & & & & & & & \\
\hline $\mathrm{T} 4$ & & .790 & & & & & & & & & & \\
\hline $\mathrm{T} 1$ & & .771 & & & & & & & & & & \\
\hline T3 & & .749 & & & & & & & & & & \\
\hline $\mathrm{T} 4$ & & & .737 & & & & & & & & & \\
\hline $\mathrm{T} 1$ & & & .647 & & & & & & & & & \\
\hline $\mathrm{T} 4$ & & & .629 & & & & & & & & & \\
\hline T3 & & & .568 & & & & & & & & & \\
\hline $\mathrm{T} 1$ & & & & .767 & & & & & & & & \\
\hline $\mathrm{T} 1$ & & & & .616 & & & & & & & & \\
\hline T5 & & & & .555 & & & & & & & & \\
\hline \multicolumn{13}{|l|}{$\mathrm{T} 1$} \\
\hline $\mathrm{T} 2$ & & & & & .764 & & & & & & & \\
\hline Т9 & & & & & .727 & & & & & & & \\
\hline $\mathrm{T} 2$ & & & & & .519 & & & & & & & \\
\hline $\mathrm{T} 3$ & & & & & & .655 & & & & & & \\
\hline $\mathrm{T} 2$ & & & & & & .612 & & & & & & \\
\hline T3 & & & & & & .603 & & & & & & \\
\hline $\mathrm{T} 2$ & & & & & & & .778 & & & & & \\
\hline $\mathrm{T} 2$ & & & & & & & .736 & & & & & \\
\hline $\mathrm{T} 1$ & & & & & & & .517 & & & & & \\
\hline \multicolumn{13}{|l|}{$\mathrm{T} 2$} \\
\hline \multicolumn{13}{|l|}{$\mathrm{T} 4$} \\
\hline T3 & & & & & & & & .816 & & & & \\
\hline $\mathrm{T} 2$ & & & & & & & & .579 & & & & \\
\hline $\mathrm{T} 4$ & & & & & & & & & .701 & & & \\
\hline $\mathrm{T} 4$ & & & & & & & & & .535 & & & \\
\hline T3 & & & & & & & & & .529 & & & \\
\hline \multicolumn{13}{|l|}{ T6 } \\
\hline $\mathrm{T} 4$ & & & & & & & & & & .790 & & \\
\hline \multicolumn{13}{|l|}{$\mathrm{T} 4$} \\
\hline $\mathrm{T} 1$ & & & & & & & & & & & & .566 \\
\hline
\end{tabular}


According to the factor analysis, differentiation and principal component analysis, deletion of some poor quality of the questions after a rotation, retaining 31 questions in the questionnaire with the final eigenvalue $>$ 0.5 , can be well explained. Each topic corresponds to the load factor is $>0.5$. The cumulative explanatory variable is $81.785 \%$. And through the exploratory factor analysis, the original 10 value dimensions were consolidated to fit into the following categories: honesty and trustworthiness, civilization, love, unity and helpfulness, honor, respect as six new moral value dimensions. So we compiled the formal "Chinese College Students' Moral Values Identity Scale". The scale has high reliability and good validity and it is suitable for measuring China's College students' moral values.

\section{Measuring the Moral Values of Chinese College Students}

We then use this self-made scale, i.e. Chinese College Students' Moral Value Identity, to measure moral values of students in six universities, namely Sun Yat Sen University, Beijing Normal University, South Xinjiang Normal University, Guangdong University of Foreign Studies, Chinese University of Science and Technology, and Changsha Normal. We sent 800 copies formal questionnaire to full-time undergraduate students, 768 valid questionnaires were collected from respondents, of whom 398 were males and 370 females. The efficiency rate was $96 \%$ and the scale reliability Cronbach alpha coefficient was 0.901 . Besides, the split half reliability was 0.877 , which indicated a good reliability and validity. Using Likert 5-scoring method in groups as a unit of measurement, data collected from questionnaires were processed with SPSS16.0 statistical processing. On the basis of known good reliability and validity of Chinese college students' moral values, the descriptive statistics of the measurements were acquired. Results are shown in Table 3.

\begin{tabular}{llllll}
\hline & $\mathrm{N}$ & Min & Max & Mean & Std. Dev \\
\hline The total score & 768 & 2.61 & 4.80 & 4.155 & 0.418 \\
Honesty and Trustworthiness & 768 & 2.41 & 5.10 & 4.256 & 0.455 \\
Civilization & 768 & 2.10 & 5.10 & 4.192 & 0.548 \\
Love & 768 & 2.23 & 5.10 & 3.917 & 0.601 \\
Unity and Help Others & 768 & 2.33 & 5.10 & 4.044 & 0.524 \\
Filial piety & 768 & 1.65 & 5.10 & 4.131 & 0.516 \\
Respect & 768 & 2.55 & 5.10 & 3.894 & 0.479 \\
Valid & 768 & & & & \\
\hline Table 3. Overall situation of moral values of Chinese college students. & &
\end{tabular}


From Table 3, we can see the scores of Chinese college students in the six dimensions of moral values ranked from high to low, followed by honest, self-discipline of civilization, filial piety, uniting to help others, love and respect. From the Table 4, gender classification grouping statistics shows that the scores of male students were higher than female university students, which can be explained as the fact that the make students' value tendency is more obvious:

\begin{tabular}{llllll}
\hline & Sex & $\mathrm{N}$ & Mean & Std.Dev. & Error \\
\hline The total score & Male & 398 & 4.120 & 0.378 & 0.018 \\
& Female & 370 & 4.005 & 0.413 & 0.012 \\
Honesty and Trustworthiness & Male & 398 & 4.331 & 0.389 & 0.021 \\
& Female & 370 & 4.196 & 0.521 & 0.023 \\
Civilization & Male & 398 & 4.232 & 0.527 & 0.024 \\
& Female & 370 & 4.145 & 0.566 & 0.031 \\
Love & Male & 398 & 3.975 & 0.615 & 0.031 \\
& Female & 370 & 3.853 & 0.580 & 0.029 \\
Unity and Help Others & Male & 398 & 4.077 & 0.510 & 0.024 \\
\multirow{2}{*}{ filial piety } & Female & 370 & 4.075 & 0.516 & 0.027 \\
& Male & 398 & 4.173 & 0.475 & 0.023 \\
Respect & Female & 370 & 4.080 & 0.535 & 0.029 \\
& Male & 398 & 3.896 & 0.471 & 0.023 \\
& Female & 370 & 3.895 & 0.487 & 0.026 \\
\hline
\end{tabular}

Table 4. The statistics for status of the moral values of Chinese men and women students and group.

The independent samples $\mathrm{T}$ test shows that Chinese male college students differed significantly in four moral value dimension, namely honest, self-discipline of civilization, love and filial piety, with Chinese female college students. And in unity and help other and respect, there is no significant difference, as shown in Table 5:

\begin{tabular}{llll}
\hline & Sex & $\mathrm{t}$ & $\operatorname{Sig}(2$-tailed $)$ \\
\hline The total score & Male & 3.186 & 0.001 \\
& Female & 3.173 & 0.002 \\
Honesty and Trustworthiness & Male & 4.209 & 0.000 \\
& Female & 4.055 & 0.000
\end{tabular}




$\begin{array}{llll}\text { Civilization } & \text { Male } & 2.108 & 0.026 \\ & \text { Female } & 2.187 & 0.026 \\ \text { Love } & \text { Male } & 2.717 & 0.004 \\ & \text { Female } & 2.810 & 0.004 \\ \text { Unity and Help Others } & \text { Male } & 1.816 & 0.059 \\ & \text { Female } & 1.921 & 0.059 \\ \text { Filial piety } & \text { Male } & 2.486 & 0.012 \\ & \text { Female } & 2.472 & 0.012 \\ \text { Respect } & \text { Male } & 0.692 & 0.425 \\ & \text { Female } & 0.790 & 0.425\end{array}$

Table 5. Independent sample T test.

\section{Experiment Conclusion}

(a) There is a sequence tendency in the moral values of Chinese College Students.

The score of moral values of Chinese college students in six dimensions ranks from high to low, from honest compliance, self-discipline of civilization, filial piety, unity and help people, to kindness and respect. It suggests that the existence of obvious orientation in the identity of moral values. People recognize and expect the honesty most. Since actual indifferent awareness of integrity in society caused strong repercussions, the evidence of students' losing trust, cheating in exams, breaching employment contract occurs frequently, which have serious negative impact on the students who should have established their social roles and social recognition. We need to awaken their attention to the concept of integrity. The sequence of value ranking i.e., selfdiscipline of civilization, filial piety, unity and helpfulness, love and respect, accurately reflects their priorities in moral values identification process. At the same time, the average score of male students is higher than female students, which can show that male is obviously higher than that of female students in value orientation.

(b) There are gender differences in moral values for Chinese students.

Table 5: Independent sample $\mathrm{T}$ test results showed that male and female college students in China, the $\mathrm{P}$ values about honest compliance, self-discipline of civilization, charity, honor were $0.000,0.026,0.004$ and 0.012 which respectively indicate that the significant difference between the levels $(\mathrm{P}<$ 0.05), and male's scores in these four dimensions of value are higher than females. That is to say, the identity of male students to honest compliance, selfdiscipline of civilization, charity, and honor is higher than that of female 
students. But in the two dimensions of uniting to help others and respect, male and female students does not show any significant differences. The possible reason is caused by gender in Chinese characters and differences. In China's traditional culture and customs of life, men have been in a dominant position in fact, and women gain the peer psychological position with male. The concept that male has superiority has existed for a long time; thereby it has extended deep into the society, which has different perception of male and female roles and responsibilities. Generally, male should be the indomitable, indomitable willpower and lofty aspirations, bear more social responsibility, restrict and develop himself with the virtues of honesty, exhibit excellence in the quality of civilization, and seek social respect and generous returns. At the same time, he should also be filial to parents, the "idol" of wife and the role of dignified father. For Chinese women, they are not supposed to undertake more complex supporting role, their social responsibility is more fixed in a traditional family roles. The concept of social roles perceived from family and society was sent out to the students through selecting spots with that in entire areas. With a long-time influence, it also makes the role of responsibility conscious in college students' mentality, rooted and germinated there, and the role of self-concept grow inside. So male students in compliance, honesty and self-discipline, benevolence and filial piety, these four moral value dimensions showed that female college students have higher cognitive level. And in recent years, China's college students' moral level continues to decline, the anomie behavior occurs at times which is the dilemma for college students, it is also a warning, which hopefully may stimulate their sense of responsibility to reverse the decline.

\section{References}

Alasdair, M. 1984. After Virtue. Notre Dame: Notre Dame University Press.

Aquino, K. F. \& Reed, A. 2002. "The Self-Importance of Moral Identity". Journal of Personality and Social Psychology 19: 1423-1440.

Atkins, R. \& Hart, D. 2003. "Neighborhoods, Adults, and the Development of Civic Identity in Urban Youth". Applied Developmental Science 7: 156165.

Bosma, H. A. \& Kunnen, E. S. 2001. Identity and Emotion: Development Through Self-organization. Cambridge, England: Cambridge University Press.

Carlo, G. \& Edwards, C. P. 2005. Nebraska Symposium on Motivation: Moral Development Through the Lifespan: Theory, Research and Application. Vol. 51. Lincoln, NE: University of Nebraska Press.

Dewey, J. 1969. Moral Principles in Education. Boston, New York: Houghton Mifflin Company. 
Gibbs, J. C. 2003. Moral Development \& Reality: Beyond the Theories of Kohlberg and Hoffman. Thousand Oaks, CA: Sage.

Haidt, J. 2001. "The Emotional Dog and Its Rational Tail: A Social Intuitionist Approach to Moral Judgment". Psychological Review 108(4): 814-834.

Nunner-Winkler, G. 1998. "The Development of Moral Understanding and Moral Motivation". International Journal of Educational Research 27: 587603.

Walker, L. J. \& Henning, K. H. 2004. "Differing Conceptions of Moral Exemplarity: Just, Brave, and Caring. Journal of Personality and Social Psychology 86: 629-647. 


\title{
Zhu Hai-Long (Guangdong University of Foreign Studies)
}

\section{The Compilation and Execution of a Measurement of Chinese Undergraduates' Moral Values Approval}

\begin{abstract}
The study completes the compilation of the questionnaire on Chinese undergraduates' moral values from six moral values dimensions: honesty and compliance, civility and self-discipline, love, unity and be helpful, esteem and filial respect. The questionnaire has 31 questions in all, taking advantage of Likert scale. Using this scale, its alpha reliability reach 0.887 with clear internal structure. The validity is well and the model fitting index accords with statistical measurement, which covers the shortage of empirical study on Chinese undergraduate students' moral values. The measurement, which focused undergraduate moral values, is compiled by a total of 768 valid samples from 6 colleges. Measurement results show that there are sequences of orientation on Chinese undergraduates' moral values approval, and the order is: Honesty and compliance, civility and discipline, filial respect unity and be helpful, love and esteem; while gender differences do exist. The male undergraduates' identity level of honesty and compliance, civility and self-discipline, love, and filial respect ranks higher than that of female undergraduates; however, the differences, between male and female undergraduates, on unity and being helpful, as well as esteem are not significant.
\end{abstract}

Keywords: Chinese undergraduates, morality, values, approval, compilation, measurement.

Ethics in Progress (ISSN 2084-9257). Vol. 6 (2015). No. 1, pp. 93-103.

doi: 10.14746/eip.2015.2.7 